\title{
NARRATIVA DAS RELAÇÕES ENTRE CURRÍCULO E CULTURA DIGITAL EM TEMPOS DE PANDEMIA: UMA EXPERIÊNCIA NA PÓS-GRADUAÇÃO
}

\author{
THE NARRATIVE OF THE RELATIONSHIP BETWEEN THE CURRICULUM AND \\ DIGITAL CULTURE DURING THE PANDEMIC - A POST-GRADUATE EXPERIENCE
}

\author{
NARRATIVA DE LAS RELACIONES ENTRE CURRÍCULO Y CULTURA DIGITAL EN \\ TIEMPOS DE PANDEMIA: UNA EXPERIENCIA EN EL POSGRADO
}

\author{
Maria Elizabeth Bianconcini de Almeida \\ Pontifícia Universidade Católica de São Paulo - Brasil
}

\begin{abstract}
Resumo: Este artigo tem o objetivo de refletir acerca da integração entre o currículo e as tecnologias e a composição da categoria " web currículo", considerado um constructo teórico e uma categoria de ação trabalhada pela autora desde 2010. Tem como base a experiência na docência de uma disciplina desenvolvida remotamente em um programa de pós-graduação no decorrer do primeiro semestre de 2020, com estudantes do curso de doutoramento. O desenho metodológico do estudo descreve o panorama bibliográfico e documental sobre a educação durante a pandemia e os conceitos que fundamentam as reflexões. Em seguida, constrói uma narrativa da experiência da autora com base em diários pessoais e documentos disponíveis no ambiente virtual que foram produzidos ao longo do desenvolvimento das atividades da disciplina. A narrativa aponta que a educação remota oportunizou outros modos de desenvolver uma educação baseada em fundamentos dialógicos, reflexivos e de coconstrução de conhecimento. Além disso, mostra a relevância da adoção de uma postura de acolhimento, solidariedade, encorajamento, criatividade e criticidade comprometida com o enfrentamento da realidade cruel da pandemia, que escancara e amplifica as disparidades sociais, culturais, digitais e educacionais.
\end{abstract}

Palavras-chave: integração currículo e tecnologias. web currículo. diálogo

\begin{abstract}
The purpose of this article is to reflect on the integration between the curriculum and technology and the composition of the category "web curriculum", considered a theorical construct and a category of action that incorporates the activities undertaken by the author since 2010 . This is based on the experience of teaching a subject that is carried out remotely in a post-graduate program with students doing a $\mathrm{PhD}$ course during the first semester of 2020. The methodological design of the study provides a bibliographical and documentary overview of education during the pandemic, as well as the concepts that underpin the reflections. Following this, there is a narrative account of the author's experience based on the personal registers and documentation available in the virtual environment, which were produced while the lesson activities were being carried out. The narrative underlines the fact that remote education has offered opportunities for other means of conducting an education that is founded on principles involving dialogue, reflection, and the co-construction of knowledge. In addition,
\end{abstract}


it shows the importance of adopting a welcoming stance, a feeling of solidarity, encouragement creativity and a critical outlook in the face of the cruel circumstances of the pandemic which have led to a widening of social, cultural, digital, and educational disparities.

Keywords: integrating technology and curriculum. web curriculum. dialogue

Resumen: Este artículo tiene el objetivo de reflexionar sobre la integración currículo y tecnologías y sobre la composición de la categoría web currículo, constructo teórico y categoría de acción trabajada por la autora desde el 2010. Tiene como base la experiencia en la docencia de una disciplina desarrollada remotamente en un programa de posgrado en el transcurso del primer semestre del 2020, con alumnos del curso de doctorado. El diseño metodológico del estudio describe el panorama bibliográfico y documental sobre la educación durante la pandemia, así como los conceptos que fundamentan las reflexiones. En seguida, construye una narrativa de la experiencia de la autora basada en diarios personales y documentos disponibles en el ambiente virtual que fueron producidos durante el desarrollo de las actividades de la disciplina. La narrativa apunta que la educación remota permitió otros modos de desarrollar una educación basada en fundamentos dialógicos, reflexivos y de co-construcción de conocimiento. Además, muestra la relevancia de la adopción de una actitud de acogida, solidaridad, incentivo, creatividad y criticidad comprometida con el enfrentamiento de la cruel realidad de la pandemia, que deja al descubierto y amplifica las disparidades sociales, culturales, digitales y educativas.

Palabras claves: Integración currículo y tecnologías; web currículo; diálogo.

\section{Introdução}

Ao iniciar o período letivo do primeiro semestre de 2020 pareciam distantes da realidade de países tropicais das Américas as informações sobre uma epidemia provocada pelo vírus SARS-COV-2 ou novo Coronavírus causador da doença denominada COVID-19, que atingia violentamente partes da República Popular da China, em especial Wuhan, na província de Hubei, e adentrava no continente europeu, alastrando-se por diversos países. Em virtude da rápida disseminação mundial do vírus a Organização Mundial de Saúde (OMS) caracterizou a crise sanitária como pandemia e recomendou o isolamento social. Entre final de janeiro e início de fevereiro de 2020 foram detectados os primeiros casos no Brasil, a princípio nem percebidos pela imprensa e menos ainda pelo público focado nos festejos e feriados carnavalescos.

Passadas as festas, a população começou a ter ciência de que o vírus havia chegado ao Brasil, inicialmente concentrado no município de São Paulo com grandes possibilidades de não se alastrar segundo alardeava o governo brasileiro, que assumiu uma postura negligente e negacionista diante da gravidade da pandemia, em manifestações públicas contrárias às recomendações da OMS. O vírus não parou em São Paulo e rapidamente a população tomou conhecimento de sua circulação pelo Brasil e mundo afora, trazendo dor, morte, insegurança e transmissão comunitária, mantendo-se dividida entre o negacionismo e a adoção de medidas 
profiláticas. O coronavírus tornou-se assim contemporâneo na partilha de contradições mediante uma nova concepção de contemporaneidade consoante "uma visão holística, sem ser unitária, diversa sem ser caótica, que aponta em geral para a copresença do antinómico, [...] do medo e da esperança, do indivíduo e da comunidade [...]" (SANTOS, 2020, p. 28).

Em face dessa realidade foram adotadas medidas restritivas à mobilidade das pessoas, fechamento de organizações comerciais, recreativas, culturais e educacionais, mantendo em funcionamento os serviços essenciais de atendimento à população. $\mathrm{O}$ fechamento das instituições educacionais brasileiras levou à adoção do ensino remoto mediado por tecnologias analógicas e digitais de informação e comunicação ${ }^{1}$, ou à suspensão do período letivo em andamento, penalizando a aprendizagem, nomeadamente das populações mais vulneráveis.

Seguindo determinações governamentais, a Universidade em que atuo suspendeu as atividades acadêmicas presenciais e adotou formalmente a continuidade do período letivo com atividades remotas mediadas pelas tecnologias digitais. As atividades pedagógicas passaram a se desenvolver com suporte em plataformas computacionais acessadas via internet, como Moodle, Teams, Zoom, Google Meet e outras, fazendo uso de diferentes metodologias e recursos para desenvolver o currículo das disciplinas de distintos cursos e áreas de conhecimento, segundo os estilos e preferências de cada docente.

Diante dessa situação, como docente e pesquisadora sobre temas relacionados a currículo e tecnologias, entendi tratar-se de um momento inusitado para aprofundar estudos sobre as inter-relações entre currículo e cultura digital e a criação de web currículos, constructo teórico que emerge dessa integração, buscando desvelar os dilemas, as possibilidades e os limites evidenciados na educação remota mediada por tecnologias digitais. Isso requer primordialmente a conscientização, a denúncia e a participação em movimentos sociais em prol da superação das desiguais sociais, educacionais e digitais por meio da implantação de políticas de inclusão social e digital, que proporcionem a todos os cidadãos o acesso e o uso dessas tecnologias como direito humano universal para o desenvolvimento social, o engajamento cívico e a participação ativa na educação, na cultura e no trabalho (WARSCHAUER, 2006).

Portanto, dedico este estudo a refletir sobre a integração currículo e tecnologias e a criação de web currículo, tendo como pano de fundo a experiência da autora na docência de uma disciplina desenvolvida remotamente em um programa de pós-graduação no decorrer do primeiro semestre de 2020, com estudantes de doutoramento. O desenho metodológico deste

\footnotetext{
${ }^{1}$ As Tecnologias digitais de informação e comunicação designam os dispositivos digitais tais como computadores, notebook, tablets, telefones celulares, Ipads etc., as linguagens e mídias que veiculam, sendo chamadas neste artigo também como tecnologias digitais, TIC ou TDIC.
} 
texto pauta-se por um panorama bibliográfico e documental acerca da educação diante da pandemia seguido de uma narrativa da experiência dessa disciplina alicerçada em diários pessoais e documentos caracterizados como registros digitais gerados no desenvolvimento da disciplina, os quais se encontram disponíveis no ambiente virtual de suporte às atividades. $\mathrm{O}$ artigo está estruturado em quatro partes, além desta introdução e das considerações finais: 1 . Políticas educacionais e as práticas de instituições educacionais diante da pandemia; 2. Em torno da discussão conceitual sobre currículo e web currículo; 3. Desenho metodológico do estudo; 4. Narrativa da experiência de uma disciplina realizada na modalidade remota. De acordo com essa estrutura, o tópico a seguir trata do referencial teórico sobre currículo.

\section{Contexto das políticas e das práticas diante da pandemia}

A partir do Decreto Legislativo $n^{\circ}$ 06/2020 (BRASIL, 2020a) do Congresso Nacional, foi instaurado no Brasil o estado de calamidade pública e estabelecido o estado de exceção, com severas restrições à mobilidade das pessoas, isolamento social e descontinuidade das atividades cotidianas do comércio, da cultura e da educação.

Seguindo o protocolo adotado em outros países as instituições educacionais brasileiras foram fechadas, afetando drasticamente o ensino e a aprendizagem, penalizando, sobretudo, as populações mais vulneráveis, como os portadores de determinadas deficiências e os grupos sociais desfavorecidos economicamente, como aqueles que realizam seus trabalhos de vendedores ambulantes nas ruas, confinando-os em minúsculos domicílios onde vivem com tantas outras pessoas e enfrentam a carência de recursos básicos para a sobrevivência.

Com a Portaria $\mathrm{n}^{\mathrm{o}}$ 343, de 17 de março de 2020 (BRASIL, 2020d), o Ministério da Educação autorizou a substituição das aulas presenciais por aulas remotas no período de duração da pandemia. Por seu turno, manifestação do Conselho Pleno do Conselho Nacional de Educação (CNE/CP), exarada no Parecer n ${ }^{0}$ 5/2020 (BRASIL, 2020b), recomendou a reorganização do calendário escolar com ênfase no cumprimento dos direitos e objetivos de aprendizagem e das competências previstas na Base Nacional Comum Curricular - BNCC (BRASIL, 2017; AGUIAR, 2020), em detrimento de referências voltadas ao acolhimento e apoio ao estudante, que permitiriam atenuar os efeitos psicossociais da pandemia.

Nesse panorama, as instituições educacionais de educação básica e de ensino superior se depararam com o terrível dilema entre suspender temporariamente atividades, conceder férias coletivas a professores, funcionários e alunos ou dar continuidade às atividades por meio remoto com suporte em tecnologias digitais e analógicas. Muitas instituições procuraram 
ajustar suas práticas convencionais para a oferta do ensino remoto mediado por tecnologias, outras decidiram a princípio não oferecer tais atividades, mas o alongamento do período de isolamento social provocou a revisão dessa posição e o ensino remoto passou a ser adotado na maioria das instituições, embora sem conseguir atender à totalidade de estudantes, de modo mais drástico na educação básica.

Diversos fatores influenciaram as decisões sobre a realização ou não do ensino remoto, com destaque para: desigualdade de acesso às tecnologias e falta de fluência digital de docentes e discentes; não universalização das políticas de tecnologias na educação no Brasil (VALENTE; ALMEIDA, 2020) existentes desde final dos anos 1980; despreparo das instituições para se adaptarem ao ensino remoto; falta de apoio técnico e pedagógico aos professores; desconhecimento da parte de educadores e gestores de políticas públicas da literatura científica e de experiências mais ou menos exitosas sobre educação e tecnologias; crise política e de gestão pública com mudanças abruptas, emergenciais e erráticas, implicando desestruturação das políticas econômicas, da saúde, cultura e educação (ALMEIDA, 2020).

Aspectos semelhantes são observados por Pardo Kuklinski e Cobo (2020) com relação a universidades Ibero-americanas diante da pandemia, com destaque para a fragilidade de vínculos entre as universidades e a cultura digital em expansão na sociedade e a falta de preparo de professores para adaptar a prática pedagógica presencial para o meio digital. Esses aspectos demandam de gestores e professores empenho desmedido para dar conta do novo trabalho com a mediação de tecnologias, gerando improvisações ou reprodução de concepções e metodologias de ensino e aprendizagem adotadas no ensino presencial centradas em conteúdos descontextualizados, que já se mostravam ineficazes para responder às necessidades de estudantes.

Em contrapartida, também se observam experiências em que os professores atuam como mediadores da aprendizagem em plataformas virtuais com a cocriação de ambientes dialógicos, de partilha de experiências e sentimentos, produção colaborativa de conhecimentos e reconstrução do currículo. Tal abordagem potencializa o estabelecimento de relações entre contextos de educação formal, não formal e informal, sujeitos e objetos de conhecimento, o protagonismo de estudantes e docentes, a emergência de atos de currículo (SANTOS; CARVALHO, 2020) e de construção de web currículos (ALMEIDA, 2019; 2020).

Da maneira análoga à educação presencial, a educação remota amplifica o dilema da educação a distância orientada por distintas abordagens e fundamentos educacionais, que oscilam entre as mais instrucionais com atendimento simultâneo de grande número de estudantes e outras mais construtivas (ALMEIDA, 2019; CARVALHO; NEVADO; 
MENEZES, 2005) com pequena escala de atendimento para viabilizar o diálogo, a reflexão e a produção colaborativa de conhecimentos.

No que tange às políticas públicas, o Parecer do CNE/CP de nº 11/2020 (CNE/CP, 2020c) apresenta as diretrizes para a elaboração de calendários e protocolos especiais a serem seguidos nas atividades remotas durante a pandemia e no retorno à presencialidade, respeitando a autonomia dos sistemas de ensino e das escolas. Contudo, não se observam iniciativas da parte do Ministério da Educação (MEC) para prover a infraestrutura necessária aos sistemas de educação básica e superior para levar avante o ensino remoto e sim para pressionar o retorno às aulas presenciais independentemente do nível de contaminação social.

Critérios definidos no âmbito dos estados e municípios evidenciam o retorno lento e gradual às atividades presenciais a partir de outubro de 2020 concomitante à continuidade do ensino remoto, com autorização de pequeno percentual de estudantes presente a cada dia na instituição, rígidas medidas de higiene, controle de temperatura, distanciamento entre as pessoas e afastamento de estudantes e profissionais com sintomas indicativos de acometimento da COVID-19. A tendência da adoção do ensino híbrido no retorno às aulas poderá se prolongar enquanto durar a pandemia ou diante do surgimento de outros vírus, conforme preconizam os especialistas. Evidencia-se, portanto, a necessidade de explorar o potencial do ensino híbrido (VALENTE, 2015) por meio de conexões entre espaços físico e virtual com a participação de estudantes e professores.

Em face do exposto, refletir sobre o experienciado com a educação remota propicia a produção de conhecimentos e referências vitais para a retomada gradativa da educação presencial e a integração das tecnologias digitais na educação. Justifica-se, assim, a importância de desenvolver um estudo acerca da integração entre o currículo e as tecnologias digitais provocada pela educação remota e a constituição de web currículos, os elementos emergentes, esperados e inesperados, de modo a compreender o presente e perquirir o futuro.

É relevante registrar que as modalidades de educação presencial, remota, a distância ou híbrida não se contrapõem e são complementares. Contudo, há limites para a educação remota ou a distância no que tange a situações específicas de estágios e práticas profissionais, que demandam a presencialidade, como no caso da formação docente. Ademais, a realidade atual requer a integração das tecnologias digitais no currículo da formação inicial de professores e a análise das contribuições dessas tecnologias ao ensino, à aprendizagem e ao desenvolvimento do currículo, bem como a participação dos estudantes em contextos de educação a distância on-line, nos quais muitos deles exercerão sua profissão, aspectos que não 
se encontram presentes na maioria dos cursos de licenciatura, como apontam Gatti e Nunes (2009), Silva (2014) e outros.

No introito do desconfinamento a cultura digital se mostra presente na vida, na cultura e na educação, o que requer criticidade para não se deixar dominar pela ingenuidade da reprodução, transmissão acrítica e homogeneizadora de informações, tampouco pela tecnociência da inteligência artificial e dos algoritmos, que interferem nas ações de seres humanos, impulsionam a disseminação de fake news e vírus computacionais (SANTOS; ALMEIDA, 2020).

Isso mostra que a tecnologia é produzida, utilizada e transformada no contexto da atividade segundo as intenções humanas (VIEIRA PINTO, 2005), podendo ser empregada para a ameaça e a opressão ou para a emancipação e a dignidade, comprometida com a ética, a justiça social, cognitiva e educacional, a democracia e a tomada de decisões. A tensão entre essas duas posições pode ser enfrentada de modo socialmente sustentável, com interpretações e avaliações contextuais comprometidas com a ética, a utilização da inteligência artificial voltada ao bem social (FLORIDI et al, 2020), ao desenvolvimento humano e à melhoria da qualidade de vida para todos.

Assim, após explicitar o contexto em que se insere este trabalho, as reflexões se desenrolam em um diálogo entre teoria e prática, a partir da revisita à memória com os olhos do presente em busca de aprofundar a compreensão sobre o vivido com ênfase no currículo desenvolvido na prática na educação remota. Visa-se, assim, criar referências para o futuro em um processo interpretativo que entrelaça as dimensões cognitiva, subjetiva, social, histórica, tecnológica, política e cultural, implícitas no currículo mediado por tecnologias digitais.

\section{Em torno da discussão conceitual sobre currículo e web currículo}

A pandemia revela a importância das tecnologias digitais como meios para desenvolver a educação, descortina "a obsolescência de práticas consuetudinárias" (CHIZZOTTI, 2020, p. 221), explicita que "a escola, as tecnologias e o currículo farão parte desta nova determinação de organização do mundo" (CHIZZOTTI, 2020, p. 221) evidenciando a urgência de compreender o significado da integração entre o currículo e a cultura digital.

O currículo engloba o conhecimento e a aprendizagem, conclama compromisso social com a formação da pessoa ética, responsável e participante ativa na transformação social (GIMENO SACRISTÁN, 1994). No entanto, estudos, políticas e práticas curriculares mostram a dicotomia entre os objetivos crítico e normativo (YOUNG, 2014), a qual se torna 
mais evidente quando se trata de tecnologias e educação, cujos processos se desenvolvem com a mediação das TIC, das quais a qualquer momento pode-se recuperar os registros digitais.

Ademais, o conteúdo do currículo é definido em distintas instâncias associadas a decisões e escolhas, que iniciam no âmbito macro das políticas públicas com a seleção prévia de objetivos e conhecimentos (atualmente também competências e habilidades) explicitados nas propostas curriculares. Os ditames do currículo oficial são recontextualizados (BERNSTEIN, 1996) na elaboração da política curricular de estados e municípios, no projeto pedagógico da unidade educacional, no planejamento do professor e em sua reconstrução na prática social pedagógica.

A recontextualização do currículo na prática pedagógica e no diálogo entre professores, alunos e objetos de conhecimento propicia a compreensão da experiência cotidiana dos participantes em articulação com o conhecimento sistematizado das áreas de saber, a elaboração de sínteses, generalizações e interpretações do mundo, favorecendo a democratização do “conhecimento poderoso" (em vez do conhecimento dos poderosos) (YOUNG, 2014, p. 201).

A inter-relação entre o "conhecimento poderoso" (YOUNG, 2014, p. 201) e a "relevância" do currículo (ROLDÃO; ALMEIDA, 2018) perpassa por todas as instâncias envolvidas com as opções curriculares em uma dupla perspectiva. Uma delas trata do currículo legitimado, comprometido com a estabilidade, a estrutura e a organização, perpetra o saber escolar preestabelecido e desencarnado; a outra perspectiva refere ao "[...] significado social e pessoal do que se ensina para quem aprende" (ROLDÃO; ALMEIDA, 2018, p. 94). A tensão entre essas duas perspectivas - proposta curricular e relevância para os estudantes - pode ser solucionada no desenvolvimento do currículo, quando se cotejam interesses, necessidades e conhecimentos prévios dos estudantes com as aspirações da comunidade escolar registrada no projeto pedagógico e com a proposta curricular oficial.

Entretanto, o selo indelével da Base Nacional Comum Curricular da Educação Básica - BNCC (BRASIL, 2017) tem como marca a centralidade curricular. Ao reverenciar o currículo na prática como implementação em oposição aos estudos teóricos sobre o currículo (LOPES, 2018), a BNCC desconsidera a diversidade de contextos educacionais e os conhecimentos das experiências cotidianas de professores e estudantes (CUNHA; SILVA, 2016) e mostra-se mais afeita ao "conhecimento dos poderosos".

Essa centralidade da BNCC acentua os óbices impostos pela pandemia, dificulta o acolhimento dos estudantes, o tratamento das problemáticas que afetam sua vida e coíbe a recontextualização do currículo. Ao ensejar a produção uniforme de materiais didáticos 
padronizados no formato impresso ou em produtos digitais disponíveis nos portais de educação, a autonomia e a autoria do professor se tornam mais restritas.

A despeito desses constrangimentos, o professor que assume o papel de intelectual crítico, inclusive sobre os ditames oficiais, encontra espaço para exercer a autonomia didática na busca de recontextualizar as prescrições curriculares, valorizar o diálogo com os estudantes e a problematização da "[...] realidade tal como a fazem e a refazem" (FREIRE, 2003, p. 74). As intervenções dialógicas do professor encorajam os estudantes a exercer a análise crítica, para dela extrair o conhecimento poderoso, representá-lo por meio de múltiplas linguagens, analisálo com o intuito de ampliar e aprofundar a compreensão e a percepção da realidade, ao tempo que desenvolvem a criticidade. Essa postura permite instaurar relações humanas mais solidárias, instiga os estudantes a relacionar o conhecimento cotidiano advindo do contexto sociocultural com as experiências educativas, o conhecimento sistematizado e os instrumentos culturais, entre os quais as tecnologias digitais, empregadas como instrumento cultural e linguagem mediadora da aprendizagem e do currículo.

Essa ótica se coaduna com a concepção de currículo como "[...] espaço-tempo de fronteira entre saberes" (MACEDO, 2006, p. 105), produção cultural e tecnológica. Trata de um espaço-tempo de diálogo e "[...] negociação de posições ambivalentes de controle e resistência" (MACEDO, 2006, p. 105), com o propósito de construir um currículo transdisciplinar, que inter-relaciona as dimensões prescrita e vivida do currículo em um espaço híbrido "[...] permeado por relações interculturais e por um poder oblíquo e contingente" MACEDO, 2006, p. 106).

A assunção do conceito de híbrido, com base em Bhabha (2002), assinala um espaço intersticial produtor de identidades e culturas fundado no diálogo estabelecido no agrupamento de discursos, tecnologias, metodologias, espaços e tempos, compondo uma força transgressora do discurso dominante (MACEDO, 2006; ALMEIDA, 2019).

A mediação das tecnologias digitais impulsiona a geração de conexões entre distintos contextos produtores de conhecimento científico e cotidiano, teoria e prática, formação e trabalho, tornando-se mais condizente com a realidade das instituições educacionais e trazendo contributos significativos para a educação, a distância, remota ou híbrida. Logo o híbrido em educação engloba tanto a inter-relação presencial e virtual, como o acoplamento de distintas metodologias, tecnologias e territórios, estimulando a formação no entre-lugar entre as instituições formadoras e escolas ou outros espaços de exercício da prática docente (NÓVA, 2017). 
A heterogeneidade reinante nas instituições educacionais em que coabitam diversas culturas, contextos, recursos e pessoas no exercício de distintos papéis (gestores, professores, funcionários, alunos, pais), tonou-se mais visível diante da inclemência da pandemia, que acelerou a imersão na cultura digital e desvelou a integração/desintegração do currículo com as tecnologias digitais.

Assim como outras culturas, a cultura digital se constitui nas práticas sociais em que coexistem distintos contextos, atividades, culturas, conhecimentos e processos (GEERTZ, 1989). Logo, não há uma cultura ou a substituição de uma cultura por outra e sim um entrelaçado de culturas, que se realimentam e se integram com a cultura digital, entendida como uma "[...] unidade aberta e em evolução [...] na zona de contato entre o digital, o de massa e o popular, gerando terceiros espaços [...]" (BUZATO, 2010, p. 83).

Agir na cultura digital demanda a apropriação das tecnologias digitais com significado pessoal, social, cultural, político, educacional e econômico, que viabilize identificar suas contribuições, riscos e oportunidades em uma postura cidadã (ALMEIDA, 2020). Isso requer compreender o significado de "estar e não estar" (DUSSEL, 2010, p. 19) em todo lugar e o tempo todo, com uma "presença digital contínua" (BURBULES, 2014, p. 2) facultada pela onipresença ou ubiquidade das tecnologias digitais, que propiciam o "estar junto virtual" (VALENTE, 2002). A ubiquidade inerente à cultura digital se mostra essencial para enfrentar o confinamento social imposto pela pandemia ao permitir que uma pessoa esteja sempre ao alcance de outra para dialogar, apoiar, compartilhar sentimentos e problemáticas e ajudar na busca de caminhos para enfrentá-las em sua real dimensão.

Em suma, a cultura digital acarreta mudanças basilares e determinantes nas práticas sociais, nas formas de criar/recriar conhecimentos, intercambiar culturas, compartilhar saberes, experiências e emoções, interferindo no cerne do currículo (ALMEIDA, 2019), aspecto evidenciado nas atividades educacionais remotas.

A complexidade e os conflitos inerentes à convivência com múltiplas culturas e contradições sociais se associam com os sofrimentos e abalos psicossociais advindos da pandemia, evidenciando nas redes sociais virtuais as constituições social e cultural dominantes e o silêncio dos desfavorecidos. Paradoxalmente, essas redes também oportunizam aglutinar pessoas em movimentos sociais em prol de ações voltadas à superação dessas mazelas, bem como do desenvolvimento de currículos contextualizados e emancipatórios em uma perspectiva dialógica, reflexiva e (re)construtiva.

Currículo e tecnologias na cultura digital têm sido objeto de estudos de Almeida (2010, 2014, 2016, 2019, 2020) com relação ao desenvolvimento de processos interativos, iterativos e 
reconstrutivos em que tecnologias e currículo se imbricam e provocam transformações mútuas, compondo web currículos, conceito e categoria de ação em contínua evolução em virtude das propriedades constitutivas de seus componentes - currículo, tecnologia e cultura digital. Nessa acepção, o currículo é o orientador e organizador de atividades mediadas pelas tecnologias digitais, cujas linguagens, sistemas de signos e funcionalidades estruturam e reconfiguram o currículo, ao tempo que este provoca transformações nos modos de comunicação e produção com as tecnologias e no redesign das redes que suportam o desenvolvimento de web currículos.

O constructo web currículo simboliza um pacto com a vinculação teoria e prática, com aportes para a compreensão e exploração dessa integração na reconstrução de currículos multiculturais, consentânea com o conhecimento poderoso de Young (2014) e com a constituição de currículos itinerantes (PARASKEVA, 2018) e errantes (CASALI, 2020) em direção a um projeto criativo comprometido com a justiça social, cultural, cognitiva, educacional e curricular. Essa reconstrução impele o rompimento dos limites disciplinares, viola as fronteiras do currículo formal, pressiona a rigidez de suas paredes e dos muros da instituição educativa, transformada em um conceito bem mais amplo ao vincular culturas, conhecimentos, tempos, espaços e contextos, do que um espaço-tempo concreto (PÉREZ GÓMEZ, 2015) e de um lugar tradicional de ensinar e aprender.

Romper as fronteiras disciplinares, institucionais e espaço-temporais implica mudança no papel do professor, que se torna criador e gestor de contextos de aprendizagem híbridos integradores de contextos de educação formal, não formal e informal, virtuais e presenciais, por meio da combinação de metodologias, tecnologias, recursos e conhecimentos, com intencionalidade pedagógica. O professor desafia o aprendiz a lançar-se ao mundo em busca de apreender o desconhecido, pensar por si mesmo, desenvolver a criticidade, a criatividade e a empatia, construir currículos itinerantes e web currículos.

A crise causada pela pandemia desvenda as assimetrias da constituição social prevalente que sentencia a exclusão social e digital, bem como escancara novas questões curriculares em matéria de práticas e teorias em prol de uma ecologia de saberes (SANTOS, 2007), que suscita a esperança no reconhecimento de uma "teoria da tradução", com o intuito de "[...] reconstruir o discurso das práticas emancipatórias" e escapar das "armadilhas da reprodução" (PARASKEVA, 2018, p. 8).

A educação remota oportuniza criar caminhos para fugir dessas amarras e ampliar as possibilidades de práticas emancipatórias e da construção de web currículos na prática pedagógica. Nessa ótica, o tópico a seguir explicita a metodologia e o contexto de uma 
disciplina desenvolvida em um programa de pós-graduação no decorrer do primeiro semestre de 2020 na qual esses elementos são investigados.

\section{Desenho metodológico do estudo}

Este estudo interroga a respeito das inter-relações entre currículo e tecnologias e a constituição de web currículos, constructo teórico que emerge dessa integração e se compõe em duas vertentes, ambas de natureza qualitativa. A primeira vertente se apoia em documentos e fontes advindas da bibliografia, conforme enfatizado nos tópicos anteriores com relação ao enquadramento social, político e educacional da pandemia, que provocou o ensino remoto mediado por tecnologias. A outra vertente refere a uma narrativa reflexiva sobre a experiência da autora na docência de uma disciplina ministrada em programa de pós-graduação no primeiro semestre de 2020, testemunho de acontecimentos da própria prática em interação com estudantes de doutoramento em educação de uma universidade. Trata-se de uma história construída a muitas mãos em um contexto sócio-histórico e institucional específico, que clama um olhar reflexivo para a reconstrução da experiência a partir da fruição de acontecimentos, que congrega sentimentos díspares entre a intensificação do diálogo e a solidão, a dedicação ao trabalho para criar atividades prazerosas para e com os estudantes e o cansaço devido ao intenso uso das telas, a reformulação do planejamento inicial de aulas presenciais para o meio digital e as inúmeras reuniões de colegiados, comissões e gestão acionadas com vigor devido ao inusitado da situação.

A narrativa se compõe na relação dialética com a experiência reconstruída valendose da memória sobre a docência e a reflexão que flui na produção deste texto (BRUNER, 1991; CUNHA, 1997; ALMEIDA; VALENTE, 2012), em diálogo com vozes da instituição, dos estudantes e das teorias subjacentes aos temas aflorados na narrativa, propiciando atribuir novos significados e sentidos à experiência e tecer conjecturas. Diversos autores utilizam a própria narrativa como objeto de investigação, como Camas, Souza e Costa (2020), Rodrigues (2017) e Cerqueira (2014).

Bruner $(1991,2008)$ distingue a narrativa de uma ação descritiva ao considerar a narrativa uma representação de ações intencionais no âmbito de determinada cultura por meio de instrumentos simbólicos disponíveis, em interlocução com outros participantes dessa cultura, seus valores, práticas, concepções de mundo e significados sociais. Por sua vez, Larrosa (2011) vincula a narrativa com a contação de uma história, que agrega a ordenação dos traços do vivenciado. "Ao narrar-se, a pessoa diz o que conserva do que viu de si mesma" 
(LARROSA, 2011, p. 68), tornando-se simultaneamente “[...] o autor, o narrador e o personagem principal” (LARROSA, 2011, p. 48).

Neste estudo, a narrativa se refere à escrita da memória da autora/narradora sobre a experiência docente vivenciada na disciplina introdutória do curso de doutoramento de uma universidade denominada Seminário de Pesquisa, oferecida no primeiro semestre de 2020. A narrativa se constitui como instrumento de análise em diálogo com o diário pessoal da autora e com documentos caracterizados como registros digitais disponíveis nos ambientes virtuais de suporte às atividades da disciplina que possam aportar elementos significativos relacionados ao currículo e à sua integração com as tecnologias digitais, procurando organizá-los, estabelecer ligações entre eles e identificar a emergência de web currículos.

No processo de narrar configura-se "[...] uma sensibilidade ou, em definitivo, uma forma humana singular de estar no mundo, que é por sua vez uma ética (um modo de conduzirse) e uma estética (um estilo)" (LAROSSA, 2002, p. 27). A presente narrativa engloba os caminhos percorridos, as atividades realizadas, as aprendizagens e o currículo, que se constitui como "currículo narrativo" (GOODSON, 2010) desenvolvido com a mediação de tecnologias digitais em uma disciplina realizada remotamente. Coerente com essa perspectiva, a seguir, apresenta-se a narrativa da autora sobre a experiência na disciplina, seu contexto e as atividades relevantes em diálogo com documentos advindos de registros digitais produzidos no desenvolvimento da disciplina, bem como com a teoria que apoia a ressignificação da experiência.

\section{Narrativa da experiência de uma disciplina realizada na modalidade remota}

Elaboro essa narrativa com o objetivo de refletir sobre a integração currículo e tecnologias no ensino remoto durante a realização da disciplina Seminário de Pesquisa, introdutória de um curso de doutoramento, e de identificar a constituição de web currículo. Para tanto, começo com a caracterização do contexto da disciplina, em seguida conto a experiência apoiada nas agendas que anunciam as atividades de cada aula, com um recorte em três momentos marcantes: início das atividades remotas, após 40 dias de atividades e no final da disciplina - em inter-relação com registros digitais de intervenções nos ambientes virtuais em que se desenvolveram as atividades da disciplina e com anotações de meu diário pessoal.

\section{$O$ contexto da disciplina}

O curso de doutorado em educação da Universidade tem três disciplinas introdutórias com forte correlação e complementaridade, entre elas uma delas é a disciplina Seminário de 
Pesquisa, contexto empírico deste estudo em sua oferta no primeiro semestre de 2020, realizada com a responsabilidade desta autora e quatorze alunos matriculados. A disciplina, planejada para se desenvolver presencialmente, com carga horária de três horas-aulas em um dia da semana, tem o propósito de instrumentalizar os doutorandos no desenvolvimento de suas pesquisas, por meio do estudo, apresentação e discussão de aspectos teórico-metodológicos.

Após duas semanas letivas, as aulas foram suspensas devido à pandemia e foi instituído o ensino remoto com atividades acadêmicas mediadas por plataformas virtuais, principalmente Teams, Moodle, Zoom, Whatsapp e outros recursos digitais como Skype, Youtube. De acordo com o Plano de Ação Imediata concebido pela linha de pesquisa de Novas Tecnologias em Educação (NTE) do Programa de pós-graduação em tela, cada disciplina tinha um monitor voluntário (estudante de mestrado ou doutorado) para auxiliar na organização do trabalho e apoiar professores e colegas nas questões técnicas. Apesar das mudanças e incertezas daquele momento, eu sentia certo conforto como pesquisadora e docente sobre temas relacionados a tecnologias e educação, educação a distância, currículo e tecnologias e web currículo, entre outros, com vasta experiência em educação a distância on-line, em especial, na formação continuada de professores.

De partida, entendi que a prática pedagógica remota não corresponde à Educação a Distância (EAD) tradicional, uma vez que o caráter de flexibilidade da nova prática diz respeito apenas ao espaço físico das atividades transposto para o meio digital com a mediação de tecnologias, mas o tempo para a realização das aulas permanece inalterado conforme o planejamento acadêmico inicial.

Os conhecimentos produzidos há mais de 20 anos associados com minhas experiências, pesquisas, publicações e coordenação de projetos de formação continuada de educadores voltados à integração de tecnologias na prática pedagógica, na gestão escolar e na pesquisa (ALMEIDA, 2019) ofereceram os alicerces para recontextualizar as atividades previstas e dar continuidade ao semestre letivo por meio da educação remota on-line, zelando para "não deixar ninguém de fora" (ALMEIDA, 2020) e ajudar os estudantes a participar dessa nova experiência.

\section{A experiência de educação remota na pós-graduação}

Condizente com os conhecimentos construídos e com as experiências anteriores, optei por desenvolver ações nos ambientes virtuais com ênfase no diálogo, na partilha de experiências e na construção colaborativa de conhecimentos. Nessa acepção, procurava propor atividades instigadoras da sociabilidade, coparticipação, solidariedade e convivência harmônica, que 
permitissem aprender e atenuar os efeitos psicossociais da pandemia (ALMEIDA, 2020), aspectos que remetem ao acolhimento e à hospitalidade, pressupondo uma relação de reciprocidade e respeito à dignidade humana segundo a ética da alteridade (DERRIDA, 2003).

Como habitualmente ocorre em minhas disciplinas, utilizo a plataforma Moodle para a organização de materiais de apoio, produções dos alunos e eventuais discussões assíncronas. Nessa disciplina, o Moodle adquiriu um papel preponderante como organizador das agendas que anunciavam previamente as atividades a serem desenvolvidas nas aulas realizadas em encontros síncronos por meio da plataforma Teams. O Moodle também foi suporte para o diálogo assíncrono, o debate sobre questões relacionadas aos temas em foco e espaço de armazenamento dos materiais de apoio às atividades e das produções dos estudantes ao longo do desenvolvimento da disciplina.

A publicação prévia da agenda de cada aula adquiriu um papel central na relação pedagógica ao integrar múltiplos letramentos (imagens, vídeos, hipermídias) e distintos gêneros como poesia, música, animação, e indicar referências relacionadas com o tema em estudo que impelia o diálogo e a reflexão sobre as experiências de vida, trabalho, formação profissional, pesquisa científica e suas metodologias, de modo a suscitar relações com o tema da aula. Esses materiais de apoio estavam disponíveis em fontes diversificadas da internet, em especial artigos de periódicos digitais de acesso aberto, bases de teses e dissertações, redes sociais. Também explicitava na agenda a dinâmica das atividades a desenvolver na aula realizada por meio do Teams, alicerçada na concepção de redesign aberto e flexível a adaptações conforme interesses e necessidades manifestados pelos estudantes ou considerando alguma problemática emergente. O final da agenda anunciava a pauta da aula seguinte e respectivos materiais de leitura.

Assim, a agenda demonstrava o cuidado estético e a intenção de integrar currículo, tecnologias e cultura digital segundo os objetivos pedagógicos, as características e funcionalidades das tecnologias e recursos e os modos de interação e produção de conhecimentos por meio de múltiplos letramentos, mobilizados segundo as características das atividades. Ademais, a comunicação via Whatsapp viabilizava o compartilhamento de notícias, a resposta ágil a possíveis dúvidas e informações complementares sobre as tarefas que os estudantes deveriam executar antes da próxima aula.

As aulas eram preparadas para transcorrer por meio de processos dialógicos com o coletivo de estudantes ou para a execução de trabalhos em grupos organizados no momento da atividade a desenvolver, os quais escolhiam os ambientes ou redes sociais virtuais conforme suas preferências; posteriormente havia roda de conversa coletiva e sínteses conceituais. Os estudantes também realizaram seminários e revisão de trabalhos autorais por pares, 
acompanhados da depuração e posterior apresentação em aula pelo par. As estratégias didáticas e as tecnologias mobilizadas nas atividades eram analisadas ao final da atividade com relação às suas contribuições ao ensino, à aprendizagem e ao desenvolvimento do currículo, às dificuldades e potencialidades evidenciadas. Ademais, eram identificados temas e contextos de pesquisa que afloravam na educação remota e as possibilidades de utilizar redes sociais da internet para alcançar possíveis participantes das investigações, uma vez que as instituições educacionais se encontravam fechadas.

Os temas do currículo proposto versaram sobre: o que é uma tese e seus principais componentes; a pesquisa em educação no Brasil; pesquisa quantitativa, qualitativa e qualiquantitativa; bases de periódicos científicos e uso de software para a gestão de referências bibliográficas; revisão sistemática de literatura; métodos de pesquisa em educação e currículo; coleta e análise de dados e cuidados éticos; projeto de pesquisa: estrutura e delineamento.

$\mathrm{Na}$ terceira semana letiva foram iniciadas as aulas remotas. Uma vez que o Teams estava em fase de estruturação com a criação das salas para cada disciplina, utilizei o Skype na primeira aula síncrona, quando fiz o acolhimento dos estudantes com uma discussão geral sobre condição de isolamento social e da necessidade de reorganizar as relações pedagógicas por meio de aulas remotas, que ofereciam uma nova estrutura para o desenvolvimento do currículo com a mediação de tecnologias digitais, cujo domínio seria propiciado no andamento de nossas atividades. Os estudantes, vinculados a diferentes linhas de pesquisa do Programa, falaram sobre suas experiências anteriores com tecnologias e educação on-line e posteriormente registraram seus depoimentos no Moodle.

Nesse momento inicial, também convidei os estudantes para, após a aula síncrona, se apresentarem em um fórum criado no Moodle com a denominação "Quem sou eu". Os estudantes, afiliados a diferentes linhas de pesquisa do Programa, poderiam se apresentar por meio de frases, imagens ou vídeos e dialogar com os pares. Embora dois doutorandos fossem ligados à linha de tecnologias em educação, um terceiro informou ter experiência em educação a distância e um quarto se apresentou como especialista em Letramento Digital, apenas uma estudante apresentou-se por meio de vídeo, todos os demais usaram textos verbais sem integração com outras linguagens. A diversidade nos níveis de fluência digital requeria criar condições para que todos pudessem desenvolver habilidades tecnológicas necessárias, o que foi feito na aula seguinte com um Tour virtual pelo Moodle e no andamento da disciplina à medida que surgia a necessidade de apropriação de um novo recurso.

Apoiados em matéria publicada na Revista Pesquisa FAPESP (ANDRADE, 2019), na aula síncrona, também debatemos sobre a resistência à ciência exacerbada e conclamei os 
estudantes a analisar o lugar de sua pesquisa de doutorado e os impactos esperados nos campos científico, social e educacional.

Em seguida, abordei as mudanças impostas em nossas vidas pela pandemia e isolamento social, instigando os estudantes a se expressar livremente sobre como lidavam com tais mudanças, suas dificuldades, descobertas, aprendizagens e transformações. Convidei-os a registrar em um fórum do Moodle suas percepções diante da situação inusitada que enfrentávamos e comentar as colocações dos colegas.

As narrativas expressas pelos estudantes oscilam entre o descrédito da veracidade da pandemia e a tomada de consciência de que se trata de um momento inusitado, de projetos adiados, de cuidar de si e dos familiares, em uma circunstância que exigia cumplicidade e empatia com o outro, manter a esperança e ter compaixão com aqueles que são acometidos pela COVID-19, estão hospitalizados e pesar pelos falecidos.

Em meio aos medos de se contaminar e de perder entes queridos, encontram-se expressões de esperança, novos sentidos atribuídos à interação medida pelas tecnologias que adentram as vidas pessoais, se misturam com o recôndito dos lares e evidenciam a premência da reflexão crítica sobre a condição existencial na pandemia e a ação apropriada para sobreviver. Desvelam a problemática primordial da vida, os valores, sentimentos e emoções aflorados, que reforçaram minha opção de contemplá-los no desenvolvimento do currículo perpassado pelas tecnologias.

A par desse modo de expressar significados e sentidos da experiência, que afeta o âmago de cada ser em sua inteireza, há depoimentos sobre a incursão das tecnologias digitais conectadas no cotidiano da vida e a necessidade de reconfiguração do ensino superior, rompendo com as formas tradicionais preponderantes nas instituições com a adoção de metodologias mais adequadas a esse momento, as quais abalam a estrutura curricular dos cursos e a "zona de conforto" de estudantes e professores, que precisam enfrentar o desconhecido, reinventar suas práticas, rever conceitos, valores e crenças.

À guisa de uma síntese reconstrutiva, posteriormente teci no próprio fórum minhas reflexões sobre os registros das experiências dos estudantes, conforme extrato.

É tempo de projetos adiados, de colocar em ação as aprendizagens desenvolvidas ao longo da vida, de exercitar a paciência, o discernimento, a tolerância com o diferente, a colaboração, a solidariedade, a alteridade, a empatia, a coragem de ressignificar o próprio ser. [...] O rigor da ciência se torna decisivo nas tomadas de decisões, a despeito de pronunciamentos desprovidos da racionalidade científica [...]. O isolamento social acentua a influência das tecnologias digitais conectadas no nosso cotidiano, nos espaços de trabalho, de estudo e formação, obrigando a 
retomada dos significados e sentidos [... das] tecnologias digitais como mediadoras dos processos de interação e construção de conhecimentos. [...] Que possamos juntos continuar com o registro dessa história!

Com a intenção de promover o acolhimento e a hospitalidade dos estudantes nos ambientes virtuais iniciei a quarta aula com um vídeo do YouTube no qual Paul McCartney conta a história da criação da música Let it be (deixa estar) a partir de um sonho que sua mãe dizia: - Vai ficar tudo bem. Deixa estar! O vídeo gerou uma discussão coletiva sobre a necessidade de diálogo e solidariedade para enfrentar os desafios desse momento e investir na produção da ciência. Para familiarizar os alunos com a plataforma Moodle foi realizado um Tour Virtual com o propósito de viabilizar a apropriação de suas funcionalidades e o reconhecimento de sua estrutura na disciplina. Por fim, foram analisados artigos indicados anteriormente para leitura sobre pesquisas qualitativas, quantitativas e qualiquantitativas.

A essa altura as atividades estavam centradas na análise de metodologias utilizadas em teses sobre educação e currículo indicadas pelos respectivos orientadores. As análises versavam sobre os principais componentes da tese, em especial as metodologias adotadas, abordagens, métodos, contextos investigados e resultados alcançados e subsidiaram a escolha de elementos para aprofundamento teórico-metodológico por meio de seminários preparados pelos estudantes com minha orientação.

No bojo desses estudos, com a mediação tecnológica e o emprego de dinâmicas contextualizadas, os alunos se expressaram acerca das atividades da disciplina como uma experiência desafiadora e cansativa, de interação coletiva a fim de construir conhecimento, instigadora da apropriação para outros momentos da vida, possibilitando o autoconhecimento e uma "viagem em busca da rigorosidade metódica".

Decorrido um mês de atividades remotas a Universidade solicitou uma análise geral da experiência em desenvolvimento em todas as disciplinas a respeito dos pontos fortes, aspectos a melhorar e sugestões. Realizei um ciclo de diálogo com os estudantes a fim de que eles se expressassem livremente e posteriormente inserissem no Moodle um texto reflexivo sobre suas percepções. Os registros salientam aspectos relacionados ao contexto mundial, à aprendizagem e à educação a distância de modo amplo, à necessidade de refletir sobre crenças e valores vigentes na sociedade, o consumismo e a mobilidade das pessoas, a preocupação com a melhoria da qualidade de vida e a preservação do meio ambiente. Ademais, referem-se à tensão provocada pela pandemia e à intensificação da sensibilidade, fomentando ações humanitárias e afetando o ensino, o aprendizado, o conhecimento e a geração de novas perspectivas acerca das práticas pedagógicas e da educação a distância. 
Esses aspectos condizem com a relevância do currículo que considera o significado social e pessoal do que se aprende e de quem aprende (ROLDÃO; ALMEIDA, 2018), com a composição entre contextos de vida e de formação (ALMEIDA, 2019) propiciada pela mediação de tecnologias, que nessa etapa da disciplina também ocupavam lugar no desenvolvimento do currículo em razão da necessidade de apropriação das funcionalidades tecnológicas pelos estudantes.

Há registros sobre o reconhecimento da potência das tecnologias na disciplina para a comunicação por meio de múltiplas mídias (áudio, vídeo...), o armazenamento e partilha de materiais didáticos, de produções individuais e grupais, o recebimento de comentários dos colegas, a interlocução mediadora da professora com a adoção de metodologias ativas que proporcionam a apropriação do conhecimento e a autoria. Além disso, os estudantes exaltam a agilidade do Programa em responder à orientação institucional de adoção do ensino remoto com a mediação de tecnologias digitais, reconhecem o esforço, a dedicação e o compromisso da coordenação do Programa e dos docentes. Vários estudantes ressaltam o convívio social das aulas remotas, a amorosidade, o respeito, a ética, a solidariedade, o compromisso, a rigorosidade científica, o aprofundamento conceitual e o competente apoio da monitora, expõem o desejo do retorno às aulas presenciais, pois sentem falta de estar frente a frente com os colegas e salientam o potencial da retomada do presencial em inter-relação com o virtual.

A produção de uma narrativa de aulas remotas fundada na reflexividade crítica se coaduna com a abordagem adotada no desenvolvimento da disciplina e traz à tona a mudança referida por Freire (2003) e o potencial dinâmico da educação de se fazer e refazer. O diálogo, o questionamento e a confluência de ideias impulsionam a reflexão sobre mudanças na educação e na pesquisa e como elas podem ser ressignificadas pelos sujeitos que dela participam.

Enfim, a retomada da memória das atividades realizadas com apoio nos registros do meu diário e do ambiente virtual evidencia o reconhecimento da qualidade das atividades remotas e de elementos relacionados à apropriação e exploração das funcionalidades das tecnologias digitais para desenvolver um currículo interativo, reflexivo, (re)construtivo e contextualizado, a identificação de mudanças nas concepções dos estudantes sobre educação remota, a necessidade de disciplina individual no controle do tempo para o estudo on-line e para o desenvolvimento da pesquisa. Ademais, explicitam a identificação da integração entre os espaços virtuais da formação, síncronos e assíncronos, com os espaços de suas residências e outros locais, físicos e virtuais, habitados ou visitados pelos estudantes, além dos espaços 
virtuais criados pelas instituições em que atuam como docentes ou gestores, com informações relevantes para os temas em estudo e para reconfigurar suas pesquisas.

As aulas a seguir foram dedicadas aos temas revisão sistemática de literatura e aos fundamentos teóricos e metodológicos dos tipos de pesquisa selecionados estudados por meio de seminários apresentados por duplas de alunos.

Os relevantes significados suscitados pela abertura das aulas com imagem, vídeo, animação e palavras, que remetem às experiências de vida, de formação e de investigação em tempos de isolamento social e ao diálogo coletivo provocador de relações com o tema do currículo planejado, motivaram-me a intensificar os cuidados éticos e estéticos na elaboração das agendas. Com esse intuito procurava despertar a subjetividade acolhedora concernente às relações entre o eu e o outro, a responsabilidade e a justiça social e curricular, fortalecendo o contexto virtual habitado com os estudantes com proposições dialógicas, reflexivas e construtivas.

Como exemplo, cito a aula de 4 de junho, cuja agenda inicia com a animação Poética de Barro, de Danza (2019), que retrata o empenho de uma pequena criatura de barro para sobreviver diante de barreiras aparentemente intransponíveis. Inspirada nessa Poética, fizemos uma reflexão sobre o empenho do doutorando no desenvolvimento de sua pesquisa e a relevância de investir na qualidade do projeto, cuja elaboração, compartilhamento e depuração constituem o foco de atividades do último mês da disciplina.

Elaborei uma proposta de atividades motivada pela Teoria da Assimilação por Etapas das Ações Mentais de Galperin (NÚÑEZ; RAMALHO, 2017), de enfoque histórico-cultural, sobre tipos de atividades que predispõem o estudante a desenvolver novos conhecimentos, habilidades, atitudes, por meio de um processo evolutivo com etapas que partem da experiência social até atingir a experiência individual, sem propor um modelo fixo. A orientação adotada para viabilizar a atividade em meio virtual consistiu basicamente em: criar condições concretas para a ação e representação da ação, que no caso da disciplina em análise corresponde à representação do projeto individual de pesquisa com base nos conhecimentos apreendidos; formação de pares em que cada colega lê e comenta o projeto individual do outro; depuração do projeto individual considerando os comentários do colega e o que apreendeu da leitura do projeto dele, transformando o externalizado em internalizado. Esse processo se repetiu no coletivo da turma, quando cada estudante apresentou a versão depurada de seu projeto, recebeu comentários do professor e de colegas e teve nova oportunidade de revisá-lo.

Os estudantes se mostraram entusiasmados e engajados nessa atividade, realizando as apresentações e comentários com seriedade e atenção, evidenciando uma evolução significativa 
nos respectivos projetos de pesquisa, que pode ter sido potencializada pelas depurações sucessivas facilitadas pela plasticidade das tecnologias digitais para o fazer e refazer contínuos.

Simultaneamente à re(elaboração), apresentação e análises dos projetos coloquei em foco estudos sobre procedimentos de coleta e análise de dados com o objetivo de realimentar a produção dos estudantes a partir de referências da literatura e de experiências de outras pesquisas, porém houve uma alternância de papéis e a curadoria do conteúdo foi realizada pelos estudantes. Eles fizeram a busca e seleção de publicações sobre o tema, que eram trazidas para discussão em sala de aula e subsidiaram elaborações conceituais sobre o significado e o potencial do grupo focal na pesquisa qualitativa com a identificação da pertinência de adotar ou não esse procedimento no projeto.

$\mathrm{Na}$ avaliação feita na última aula convidei os estudantes a exercitar um olhar mais abrangente sobre a disciplina, analisar pontos fortes, aspectos a melhorar e sugestões em relação a questões de conteúdo, metodologias e tecnologias.

Por meio do diálogo, os estudantes manifestaram-se espontaneamente com as seguintes expressões sobre os pontos fortes: extensão da sala de aula presencial; ajuda da monitora na apropriação das tecnologias; exploração de diferentes tecnologias necessárias à produção da tese; diálogo entre as disciplinas introdutórias para entender o contexto da pesquisa; ferramental para desenvolver a pesquisa amparada na metodologia; dinâmicas adotadas nas aulas que permitiram entender o significado da metodologia da pesquisa e alcançar cada aluno; compartilhamento de experiências e conhecimentos; análise de diferentes tipos de pesquisa; dinâmica de estudos sobre grupo focal; parceria com o colega na avaliação do projeto de pesquisa; participação de professora e colegas nas apresentações individuais ou de grupos com sugestões levadas para outras situações; no meio do caos, reorganizamo-nos; potencial da educação de se ressignificar.

Como aspecto a melhorar identificaram o acúmulo de aulas virtuais em um mesmo dia da semana, uma vez que o horário das três disciplinas introdutórias do doutorado foi transposto para o virtual conforme planejado para aulas presenciais. Isso mostra que a flexibilização e a abertura dos espaços físicos das aulas para o meio virtual não encontraram correspondência com o tempo, que permaneceu o mesmo, provocando cansaço cognitivo e visual em discentes e docentes. A estética das agendas e a dinâmica das aulas interativas com metodologias ativas entremeadas com intervalos permitiram relativizar esse cansaço, porém demandaram maior esforço na busca de materiais de apoio de qualidade, no planejamento e na organização das agendas. Os estudantes reconheceram o esforço despendido no planejamento e organização da disciplina e sugeriram sua replicação associada a diversidade das dinâmicas das atividades 
pautadas por apresentação, discussão, explanação, reflexão, em uma alternância que clama a participação e engajamento.

Ademais, destacam a abertura do currículo para outros espaços em interface com contextos não formais e informais, a integração entre presencial e virtual, universidade e escola, atingindo múltiplas culturas e entornos virtuais constituídos com outras intenções, por exemplo, os ambientes familiares, cujos membros adentraram algumas vezes nas atividades da disciplina.

A concepção de currículo adotada na experiência da disciplina narrada, associada com as potencialidades das tecnologias digitais viabilizou a permeabilidade dos limites disciplinares e a interlocução entre as disciplinas introdutórias, evidenciando a concretização de práticas interculturais e interdisciplinares, o rompimento das fronteiras do currículo formal, a transposição dos muros das instituições por meio da reconfiguração das plataformas virtuais previamente estruturadas, seguindo a fragmentação típica da organização espaço-temporal do presencial.

A narrativa revela a composição de currículos itinerantes (CASALI, 2020; PARASKEVA, 2018) delineados à medida que se desenvolvem em inter-relação com as tecnologias digitais, provocando transformações nos currículos e nas tecnologias e constituindo web currículos expressos nas agendas, atividades desenvolvidas e narrativas singulares dos estudantes.

Contudo, não basta transpor o currículo para o meio digital em uma visão "neutra" que usa tecnologia como suporte para conteúdos e atividade confinadas entre paredes concretas ou simbólicas. Web currículo é concebido na ótica integradora e de transformações mútuas, de abertura e flexibilidade, o que requer a conscientização do significado de currículo e de tecnologia, conforme explicitado neste trabalho (ALMEIDA, 2019, 2010).

Essa reconstrução se compõe no andamento das atividades, nos movimentos não lineares dos participantes do ato educativo entre espaços virtuais de formação e presenciais de vida em família, em que vão compondo e recompondo o conhecimento, delineando trajetórias e narrativas curriculares e de aprendizagem.

\section{Considerações}

Este estudo foi elaborado com o objetivo de refletir sobre a integração currículo e tecnologias e a constituição de web currículo por meio de um estudo bibliográfico e documental para caracterizar a educação diante da pandemia e explicitar os conceitos orientadores das reflexões encetadas. Tais reflexões são aprofundadas com a narrativa de uma experiência da 
autora na docência de uma disciplina desenvolvida remotamente em um programa de pósgraduação no decorrer do primeiro semestre de 2020, com estudantes de doutoramento.

O estudo se justifica pela influência das tecnologias digitais no período de isolamento social na educação, no cotidiano, nos espaços de trabalho, de estudo e formação, compelindo a retomar os significados e sentidos da educação mediada pelas tecnologias digitais, presencial, a distância, híbrida ou remota. Portanto, o estudo oferece subsídios para a reorganização da educação com o recrudescimento da contaminação do vírus causador da COVID-19, podendo requerer novos períodos de isolamento social. Em que pesem as situações de improvisação e de reprodução de práticas transmissivas, a narrativa sobre a educação remota vivenciada traz evidências do potencial de desenvolver uma educação dialógica, reflexiva e construtiva.

É necessário revigorar a denúncia de que a pandemia escancara e amplifica problemas estruturais existentes no Brasil desde o período colonial e requer enfrentar os prejuízos causados pelas acentuadas disparidades sociais, culturais, digitais, educacionais, que tornam determinados grupos sociais mais vulneráveis. O desenvolvimento da educação mediada pelas tecnologias digitais e a expansão da cultura digital em razão do isolamento social reforçam o fosso digital (SELWIN, 2006) de segmento considerável da população alijado do acesso a bens culturais, informações e serviços veiculados via internet. Isso corrobora a premência de fortalecer a qualidade e a equidade da educação por meio de políticas orientadas ao desenvolvimento da cidadania responsável e à melhoria da qualidade de vida das populações, com a criação de espaços sem fronteiras, que contemplem a diversidade cultural, o diálogo multidirecional e horizontal, abarquem a cultura digital, os saberes cotidianos e os modos de enfrentar problemas, desenvolver experiências e lutar pelo bem comum de cada contexto. Essa postura contraria a perpetuação de uma posição teórica fixa, assume as tecnologias digitais como poiesis da vida, lançando o sujeito em direção ao infinito da representação da unicidade do ser, do pensar e dialogar de outras maneiras e delinear currículos itinerantes (PARASKEVA, 2018).

A narrativa sobre a experiência de uma disciplina de programa de pós-graduação é relevante como referência para diferentes níveis de ensino e instituições educacionais pela concretização da interlocução entre distintos recursos, espaços e plataformas virtuais destinados ao uso educacional, que passam a compor o currículo. Também adentram o currículo distintos espaços presenciais, inclusive os domésticos onde habitam professores e estudantes, reconfigurando a representação do conhecimento e explicitando as incertezas do currículo de percurso aberto, flexível, acompanhado de errâncias virtuosas (CASALI, 2000). 
Por conseguinte, a narrativa externaliza que o híbrido vai além do aninhamento de contextos de aprendizagem, presenciais e virtuais, ao constituir um espaço intersticial produtor de identidades, culturas, tempos, que se compõe na convergência de tecnologias digitais e analógicas, de lugares de prática e de formação, de metodologias diferenciadas, mobilizadas conforme intenções e características da atividade. Dessarte, a narrativa contribui para a compreensão do desenvolvimento do ensino híbrido, tendência apontada para o retorno gradual à presencialidade, desvelando o potencial de transgredir com o discurso político pedagógico dominante da homogeneização e reprodução curricular.

Ademais, a narrativa mostra o lugar do estudante em atividades dialógicas, de acolhimento, solidariedade e coconstrução de conhecimento, encorajando-os a enfrentar fragilidades, perdas e desafios, a investir na produção da ciência e acreditar nas contribuições que suas pesquisas poderão trazer para a educação como área de conhecimento científico e como prática social pedagógica direcionada à justiça social, cognitiva, educacional, curricular e digital.

Como afirma Chizzotti (2020, p. 220), “a maré digital já está provocando o chamado a um novo currículo. Ignorar essa lição, patenteada no decurso da epidemia da COVID-19, será perder o curso da história".

\section{REFERÊNCIAS}

AGUIAR, Márcia Angela da S. Impactos da pandemia da Covid-19 na educação brasileira e seus reflexos nas políticas e orientações curriculares. Revista de Estudos Curriculares, v. 11, n. 1, 2020.

ALMEIDA, Maria Elizabeth Bianconcini de. A crise educacional gerada pela Covid-19 e as tecnologias: ontem, hoje e caminhos para o futuro. In: ALMEIDA, Fernando José; ALMEIDA, Maria Elizabeth Bianconcini de; SILVA, Maria da Graça Moreira da. (Orgs.). De Wuhan a Perdizes. Trajetos educativos [livro eletrônico]. São Paulo: EDUC, PUC-SP, 2020, p. 164-179.

ALMEIDA, Maria Elizabeth Bianconcini de. Integração currículo e Tecnologias de Informação e Comunicação: Web currículo e formação de professores. (Tese de livredocência). Faculdade de Educação, Pontifícia Universidade Católica de São Paulo, São Paulo, 2019.

ALMEIDA, Maria Elizabeth Bianconcini de. Currículo e narrativas digitais em tempos de ubiquidade: criação e integração entre contextos de aprendizagem. Revista de Educação Pública, Cuiabá, v. 25, n. 59/2, p. 526-546, mai./ago. 2016.

ALMEIDA, Maria Elizabeth Bianconcini de. Integração currículo e tecnologias: concepção e possibilidades de criação de web currículo. In: ALMEIDA, Maria Elizabeth Bianconcini de; 
ALVES, Robson. M.; LEMOS, Silvana. D. V. (org.). Web Currículo: Aprendizagem, pesquisa e conhecimento com o uso de tecnologias digitais. Rio de Janeiro: Letra Capital, 2014, p. 20-38.

ALMEIDA, Maria Elizabeth Bianconcini de . Integração de currículo e tecnologias: a emergência de web currículo. In: ENDIPE - Encontro Nacional de Didática e Prática de Ensino, 15., 2010. Anais eletrônicos. Belo Horizonte: UFMG, 2010. p. 166-179.

ALMEIDA, Maria Elizabeth Bianconcini de; VALENTE, José Armando. Integração currículo e tecnologias e a produção de narrativas digitais. Currículo sem Fronteiras [online], v. 12, n. 3, p. 57-82, set./dez. 2012.

ANDRADE, Rodrigo de O. Resistência à ciência. Crise de confiança suscita debate mundial sobre como enfrentar ataques ao conhecimento científico. Revista Pesquisa FAPESP, ed. 284, out., 2019.

BHABHA, Homi K. El Lugar de la Cultura. Buenos Aires: Manantial, 2002.

BERNSTEIN, Basil. A estruturação do discurso pedagógico: classe, código, controle. Petrópolis: Vozes, 1996.

BRASIL. Congresso Nacional. Decreto Legislativo $n^{o}$. 06/2020. Brasília, 2020a.

BRASIL. Ministério da Educação. Conselho Pleno/Conselho Nacional de Educação. Parecer 5/2020. Brasília: MEC, CNE/CP, 2020 b.

BRASIL. Ministério da Educação. Conselho Pleno/Conselho Nacional de Educação. Parecer 11/2020. Brasília, MEC, CNE/CP, 2020c.

BRASIL. Ministério da Educação. Portaria $n^{\circ}$ 343, de 17 de março de 2020. Brasília: MEC, 2020d.

BRASIL. Ministério da Educação. Base Nacional Comum Curricular (BNCC). Resolução CNE/CP nº 2, de 22 de dezembro de 2017. Brasília: MEC, 2017.

BRUNER, Jerome. Construção Narrativa da Realidade. Tradução Waldemar Ferreira Netto. Critical Inquiry, v. 18, n. 1, p. 1-21, 1991.

BRUNER, Jerome. Actos de significado. Lisboa: Edições 70, LDA, 2008.

BURBULES, Nicolas C. Los significados de "aprendizaje ubicuo". Archivos Analíticos de Políticas Educativas [online], v. 22, n. 104, 2014.

BUZATO, Marcelo E. K. Cultura digital, Educação e Letramento: conflitos, desafios, perspectivas In: HÖFLING, C. (org.). Jornada de Letras. São Carlos: UFSCar, 2010, p. 6988 .

CAMAS, Nuria Pons Vilardell; SOUZA, Fernando Roberto Amorim; COSTA, Carmen Sílvia da. Narrativa de uma experiência na pós-graduação: Entre os vícios do presencial e a 
presença do digital. EM TEIA - Revista de Educação Matemática e Tecnológica Iberoamericana, Recife, v. 11, n. 2, p. 1-18, maio/ago., 2020.

CARVALHO, Marie Jane Soares; NEVADO, Rosane Aragon de; MENEZES, Crediné Silva de. Arquiteturas pedagógicas para educação a distância: Concepções e Suporte Telemático. In: Anais... XVI Simpósio Brasileiro de Informática na Educação - SBIE - UFJF - 2005.

CASALI, Alípio M. D. Por um currículo errante. In: ALMEIDA, Fernando José; ALMEIDA, Maria Elizabeth Bianconcini de; SILVA, Maria da Graça Moreira da. (Orgs.). De Wuhan a Perdizes. Trajetos educativos [livro eletrônico]. São Paulo: EDUC, PUC-SP, 2020.

CERQUEIRA, Valdenice Minatel M. Resiliência e tecnologias digitais móveis no contexto da educação básica: "senta que lá vem a história". 2014. Tese (Doutorado em Educação:

Currículo) - Pontifícia Universidade Católica de São Paulo, São Paulo, 2014.

CHIZZOTTI, Antonio. Tempos incertos. In: ALMEIDA, Fernando José; ALMEIDA, Maria Elizabeth Bianconcini de; SILVA, Maria da Graça Moreira da. (Orgs.). De Wuhan a Perdizes. Trajetos educativos [livro eletrônico]. São Paulo: EDUC, PUC-SP, 2020. p. 216221.

CUNHA, Maria Isabel. Conta-me agora! As narrativas como alternativas pedagógicas na pesquisa e no ensino. Revista da Faculdade de Educação, São Paulo, v. 23, n. 1-2, jan./dez., 1997.

CUNHA, Katia S.; SILVA, Janini P. Sobre base e bases curriculares, nacionais, comuns: de que currículo estamos falando? Revista e-Curriculum, São Paulo, v. 14, n. 4, p. 1236-1257, out./dez. 2016.

DANZA, Giuliana. Poética de Barro. Direção e produção Giuliana Danza. Rio de Janeiro: Portacurtas, 2019.

DERRIDA, Jacques. Da hospitalidade. Trad. Antonio Romane. São Paulo: Escuta, 2003.

DUSSEL, Inés. VII Fórum lationoamericano de educación: aprender y enseñar em la cultura digital. Buenos Aires: Fundación Santillana, 2010.

FLORIDI, Luciano; COWLS, Josh; KING, Thomas. C; TADDEO, Mariarosaria. Como projetar IA para o bem social: sete fatores essenciais. Science and Engineering Ethics, v. 26, p. 1771-1796, 2020.

FREIRE, Paulo. À sombra desta mangueira. 6 ed. São Paulo: Olho d'água, 2003.

GATTI, Bernadete A.; NUNES, Marina Muniz R. (orgs.). Formação de professores para o ensino fundamental: estudo de currículos das licenciaturas em pedagogia, língua portuguesa, matemática e ciências biológicas. São Paulo: FCC/DPE, 2009.

GEERTZ, Clifford. A interpretação das culturas. Rio de Janeiro: LTC, 1989. 
GIMENO SACRISTÁN, José. EI curriculum: los contenidos de la enseñanza o un análisis de la práctica? In: GIMENO SACRISTÁN, José; PÉREZ GÓMEZ, Angel I. Comprender y transformar la enseñanza. Madrid: Edicones Morata, 1994, p. 137-170.

GOODSON, Ivor F. Towards a theory of narrative learning. In: GOODSON, Ivor et al. (org.). Narrative Learning. United Kingdom: Routledge, 2010 [e-book], p. 1-10.

LARROSA, Jorge Bondía. Notas sobre a experiência e o saber da experiência. Revista Brasileira de Educação, Rio de Janeiro, n. 19, p. 20-28, jan./abr. 2002.

LARROSA, Jorge Bondía. Experiência e alteridade em Educação. Revista Reflexão e Ação, Santa Cruz do Sul, v. 19, n. 2, p. 4-27, jul./dez. 2011.

LOPES, Alice C. Apostando na produção contextual do currículo. In: AGUIAR, Márcia A.; DOURADO, Luiz F. (orgs.). A BNCC na contramão do PNE 2014-2024: avaliação e perspectivas. Recife: ANPAE, 2018, p. 23-27.

MACEDO, Elizabeth. Currículo: Política, Cultura e Poder. Currículo sem Fronteiras [online], v. 6, n. 2, 2006. p. 98-113, jul./dez. 2006.

NÓVOA, António. Firmar a posição como professor, afirmar a profissão docente. Cadernos de Pesquisa, São Paulo, v. 47, n. 166, p. 1106-1133, out./dez. 2017.

NÚÑEZ, Isauro Beltrán; RAMALHO, Betania Leite. A teoria da Formação Planejada das Ações Mentais e dos Conceitos de P. Ya. Galperin: contribuições para a Didática

Desenvolvimental. Obutchénie: Revista de Didática e Psicologia Pedagógica, Uberlândia, MG, v.1, n.1, p.70-97, jan./abr. 2017.

PARASKEVA, João M. Against the Epistemicide. Itinerant Curriculum Theory and the Reiteration of an Epistemology of Liberation. In: ULJENS, Michael; YLIMAKI, Rose M. (Eds). Bridging Educational Leadership, Curriculum Theory and Didaktik: Non-affirmative Theory of Education (Educational Governance Research). Switzerland: Springer, 2018.

PARDO KUKLINSKI, Hugo; COBO, Cristóbal. Expandir la universidad más allá de la enseñanza remota de emergência: Ideas hacia un modelo híbrido post-pandemia. Barcelona: Outliers School, 2020.

PÉREZ GÓMEZ, Ángel I. Educação na era digital: a escola educativa. Tradução Marisa Guedes. Revisão técnica Bartira Costa Neves. Porto Alegre: Penso, 2015.

PLITT, Laura. Covid-19 não é pandemia, mas sindemia. O que essa perspectiva muda no tratamento. BBC News Mundo, 10 out., 2020.

RODRIGUES, Alessandra. Narrativas digitais, autoria e currículo na formação de professores mediada pelas tecnologias: uma narrativa-tese. 2017. Tese (Doutorado em Educação: Currículo) - Pontifícia Universidade Católica de São Paulo, São Paulo, 2017.

ROLDÃO, Maria do Céu; ALMEIDA, Sílvia. Conhecimento e currículo: como se seleciona o conhecimento "relevante"? In: PACHECO, José Augusto; ROLDÃO, Maria do Céu; 
ESTRELA, Maria Teresa. (Orgs.). Estudos de Currículo. Porto: Porto Editora, 2018, p. 89127. (Coleção Educação e Formação; v. 11).

SANTOS, Boaventura Sousa. O coronavírus, nosso contemporâneo. JL Jornal de Letras, Arte e Ideias. Coluna Ideias. Ano XL, n. 1294, 6 a 19 mai., 2020. p. 28-29.

SANTOS, Boaventura Sousa. Para além do pensamento abissal: Das linhas globais a uma ecologia de saberes. Novos estudos CEBRAP, São Paulo, n.79, p. 71-94, nov., 2007.

SANTOS, Edmea; CARVALHO, Felipe. Atos de currículo emergentes na educação online. ReDoC - Revista Docência e Cibercultura. v. 4, n. 2, p. 6-12, mai./ago., 2020.

SANTOS, Priscila Costa; ALMEIDA, Maria Elizabeth Bianconcini de. Educação e fake news: construindo convergências. Revista Exitus, Santarém/PA, v.10, n. 1, p. 1-31, e020057, 2020.

SELWYN, Neil. Digital division or digital decision? A study of non-users and low users of computers. Poetics, v. 34, n. 4-5, p. 273-292, 2006.

SILVA, Selma C. de O. Formação inicial de professores e as Tecnologias Digitais da Informação e Comunicação: busca de padrões orientadores. 2014. Dissertação (Mestrado em Psicologia da Educação) - PUC-SP, São Paulo, 2014.

VALENTE, José Armando; ALMEIDA, Maria Elizabeth Bianconcini de. Políticas de tecnologia na educação no Brasil: visão histórica e lições aprendidas. [Brasilian technology policies in education: History and lessons learned]. Arquivos Analíticos de Políticas Educativas [Education Policy Analysis Archives], v. 28, n. 94, 22 jun., 2020.

VALENTE, José Armando. O ensino híbrido veio para ficar. In: TREVISANI, Fernando de M., TANZANI NETO, Adolfo; BACICH, Lilian. Ensino Híbrido Personalização e tecnologia na educação. Porto Alegre: Penso, 2015, p. 13-17.

VALENTE, José Armando. A espiral da aprendizagem e as tecnologias da informação e comunicação: repensando conceitos. In: JOLY, Maria Cristina Rodrigues Azevedo. Tecnologias no ensino: implicações para a aprendizagem. São Paulo: Casa do Psicólogo, 2002, p. 15-37.

VIEIRA PINTO, Álvaro. O conceito de tecnologia. Rio de Janeiro: Contraponto, 2005. v. 2. YOUNG, Michael. Teoria do currículo: o que é e por que é importante. Cadernos de Pesquisa, São Paulo, v. 44, n. 151, p. 190-202, jan./mar. 2014.

WARSCHAUER, Mark. Tecnologia e inclusão social. São Paulo: SENAC São Paulo, 2006. 


\section{$\underline{\text { SOBRE A AUTORA }}$}

\section{Maria Elizabeth Bianconcini de Almeida}

Livre docente em Tecnologias na Educação pela Faculdade de Educação da PUC-SP. Professora associada do Departamento de Educação, Formação, Gestão e Tecnologias, da Faculdade de Educação, da PUC-SP. Líder do Grupo de Pesquisa Formação de Educadores com suporte em meio digital. Pesquisadora produtividade do CNPq (PQ1 C). E-mail: bethalmeida@pucsp.br

(iD) https://orcid.org/0000-0001-5793-2878 